\title{
Lectura simbólica de ciertas adaptaciones del mito: de Orfeu da Conceição \\ a Orfeu Negro
}

\section{Symbolic reading of certain adaptations of the myth: from Orfeu da Conceiçao a Orfeu Negro}

\author{
Arturo Morales Campos \\ Universidad Michoacana de San Nicolás de Hidalgo \\ arturo.morales@umich.mx \\ Rodrigo Pardo Fernández \\ Universidad Michoacana de San Nicolás de Hidalgo \\ rodrigopardof@gmail.com
}

Resumen: La adaptación, o el paso de un texto cifrado en un código a otro código diferente, suele entenderse como una especie de traducción sin más. No obstante, las circunstancias sociohistóricas en las que se da esa "traducción" son altamente determinantes; es decir, algunas de las condiciones sociales bajo las que emerge el nuevo texto "adaptado" pueden integrarse y darle un sentido un tanto diferente, ya sea transcribiendo o criticando dichas circunstancias.

El presente trabajo aborda el filme Orfeu Negro (1959), de Marcel Camus, con la finalidad de analizar determinados elementos textuales: signos, símbolos, mitos, etc., comunes en el contexto que emerge dicho texto. Estos elementos le imprimen una especificidad y, en adición, una serie de referencias ideológicas que, en gran medida, se opone a la percepción tradicional de la adaptación. 
Palabras clave: Orfeo, mito, símbolo, código, película.

Abstract: It is common to understand adaptation as a simple translation. However, social-historic circumstances could be highly determining and significant within that "translation". In other words, some social conditions in which the new text emerges can be integrated and give it a somewhat different meaning: either transcribing or criticizing these circumstances.

This paper deals with the film Orfeu Negro (1959), by Marcel Camus, with the objective of analyzing certain textual elements: signs, symbols, myths, etc., common in the context that this text emerges. These elements give it specificity and, in addition, a series of ideological references, that, to a large extent, oppose the traditional perception of the term 'adaptation'.

Keywords: Orpheus, Myth, Symbol, Code, Film.

Recibido: I de julio de 2020 Aceptado: 5 de diciembre de 2020 https://dx.doi.org/IO.I 5 I 74/rv.vi 4 i29.559

\section{Preludio}

Cuando se trata de elegir una película y no otra, de entre un abanico de películas surgidas a partir de una idea planteada en una obra literaria, se lleva a cabo una discriminación, un proceso de eliminación necesaria.

Teniendo en cuenta las características de su proceso de adaptación (ver Garcia, 1990), se optó por la película Orfeu Negro, ganadora de la Palma de Oro, en Cannes, en 1959. Se trata de 
una historia que transcurre en América Latina, cuyos personajes pertenecen a un contexto sociocultural y económico que interesa especialmente destacar. Además, tiene la particularidad de ser una doble traducción (de un código a otro): del mito griego, planteado por Ovidio en Las metamorfosis y por Virgilio en sus Geórgicas (1967), a la pieza teatral Orfeu da Conceiçâao, ${ }^{1}$ de Vinicio de Moraes; posteriormente, la adaptación de la obra dramática al guion cinematográfico.

\section{De la literatura y el cine}

\section{Panorámica}

La reflexión sobre el cine desde la literatura se suele considerar como la aproximación desde un código a otro. Es común que se piense en lo literario que hay en el cine, de las influencias en uno u otro sentido (generalmente, valorándose la literatura por encima de la práctica cinematográfica) y, por supuesto, se indican las consabidas adaptaciones.

Cuando se habla de adaptación, hay opiniones diversas, no necesariamente excluyentes: en términos de Cros (1990: 5), se trata de una "ré-organisation du sens en fonction d'un nouveau système semiótico-idéologique"; ${ }^{2}$ se puede hablar de "diálogos interartísticos," a decir de Villanueva (1990: 189); en palabras de Peńa Ardid (1992: 23), el paso de un código a otro supone: "una transfiguración no solo de los contenidos semánticos sino de las categorías temporales, las instancias enunciativas y los procesos estilísticos que producen la sig-

\footnotetext{
${ }^{1}$ La traducción sería "Orfeo de la Concepción”, que podría remitir a una población cercana a Río de Janeiro.

${ }^{2}$ Esto es, "reorganización del sentido y de la función a un nuevo sistema semiótico-ideológico"; en esta cita y en las siguientes del portugués y el inglés, la versión en español es nuestra.
} 
nificación y el sentido de la obra de origen"; lo llama también "transposición fílmica" (27). La transposición "designa la idea de traslado pero también la de trasplante, de poner algo en otro sitio, de extirpar ciertos modelos, pero pensando en otro registro o sistema" (Wolf, 2001: 16). Desde esta perspectiva, se trata de sistemas de comunicación que comparten en ocasiones intenciones y constructos, pero que al cabo se conforman en la diferencia, no en la identidad o la mutua (y manida) influencia (Mac Farlane, 1996).

\section{Definiciones}

Cuando abordamos el fenómeno del cine, en las distintas aproximaciones teóricas, tenemos una variedad extraordinaria de definiciones; se hacen referencias al espectáculo cinematográfico (Ingarden, 1979); de sistema fílmico, de modelo de representación, lenguaje, de medio de expresión, de sistema semiótico; además, como destaca Villanueva, "El cine [...] es fundamentalmente [...] un arte de carácter sintético o polifónico, pues integra en un sistema único series distintas de signos, cada una obediente a diferentes códigos" (1990: 187). En este sentido, nos interesa la pervivencia de ciertos códigos a partir de temas y mitos recurrentes en la obra de Camus y sus antecedentes.

\section{Descenso a los infiernos: Orfeu negro, del mito teatral al cine}

\section{El mito}

La historia de Orfeo, a decir de diversas fuentes, es una de las más interesantes de la mitología griega en muchos aspectos, "Habiéndose formado en torno a esta interesante figura no solamente un mito, sino una verdadera secta teológica encaminada a conseguir 
una reforma tanto dogmática como moral de la religión popular griega” (Bergua, 1960: 337), referida, en este caso, a la creencia en un panteón diverso, cuyos misterios el orfismo tiende a revelar; se ha llegado incluso a sostener, bajo esta línea, que influyó en la conformación del cristianismo primitivo (en referencia a las posturas de algunos iniciadores de la iglesia cristiana, como Agustín, Lactancio y Clemente de Alejandría), lo que denota el grado de su importancia. Además, debe considerarse el simbolismo del mito de Orfeo en términos del pensamiento romántico del siglo XIX (Guthrie, 2003), con su consecuente proyección y asunción por parte del pensamiento burgués, cuya suerte de interpretación superficial y simplista llega a nuestros días (el amor, la fidelidad y, por supuesto, la belleza).

No puede soslayarse la importancia que ha tenido como motivo inspirador (esto es, referente anecdótico y simbólico) de composiciones musicales desde el siglo XVII ${ }^{3}$ hasta el día de hoy, debidas en gran medida a la exaltación de Orfeo como modelo de compositor e intérprete de música. Relata Vinicio de Moraes la génesis de su obra, cuando

Hace 16 años [se refiere a 1940], una cierta noche en casa del arquitecto Carlos León [...] después de leer en una vieja mitología el mito griego de Orfeo, daba yo inicio a los versos del primer acto, que terminé con la madrugada [...] Solo en Los Ángeles, 6 años después, conseguí encontrar el segundo y tercer actos, siendo que

${ }^{3}$ Euridice (Rinuccini, 1600); L’Orfeo (Monteverdi, 1607), considerada además como la primera ópera; Orfeo dolente (Belli, 1616); La morte di Orfeo (Landi, 1619); Orfeus und Euridice (Schütz, 1638); Orfeo (Rossi, 1647); Orfeo (Lully, 1690); Orfeo ed Euridice (Gluck, 1762); Orfeo ed Euridice (Deller, 1763); Orfeo ed Euridice (Naumann, 1786); L'anima del filosofo (Haydn, 1791); Orpheus (Liszt, 1854); Orphée aux Enfers (Offenbach, 1858); Orphée (Duchase, 1913); Orpheus und Eurydike (Krenek, 1926); Orpheus (Stravinskij, 1947). 
este último lo perdí, solo disponiéndome a rehacerlo en 1953 [...] (Moraes, 2003).

La "vieja mitología" a la que alude es La leyenda dorada de los dioses y de los héroes, de Mario Meunier, cuya primera edición es de 1923. Se hace necesario resumir en pocas líneas el mito que sirve de referencia a Moraes (recordemos que hay distintas versiones, interpretaciones de los mitos clásicos), a fin de identificar los motivos que retoma (o, mejor dicho, trastoca), en primer lugar, para la escritura de su obra Orfeu da Conceição y, más adelante, para la creación del guion de Orfeu Negro, en términos de la transposición a otro código.

La versión definitiva, más completa del mito la relata Virgilio al final de sus Geórgicas (poema escrito entre los años 37-30 a.c.; cfr. Virgilio, 2003; en español, Pérez de Montalbán, 1991). ${ }^{4}$ Narra que Orfeo era hijo de Apolo, ${ }^{5}$ y de la musa de la música, Calíope, de ahí su maestría con el canto y la lira (regalo de Apolo, y a la que añade dos cuerdas, según la tradición). Enamorado de Eurídice (ninfa o dríade), se casa con ella. Al poco tiempo, Eurídice, paseando por las orillas de un río de la Tracia, es vista por Aristeo, quien prendado de ella la persigue; ella escapa al bosque, donde es mordida por una víbora y muere. Orfeo, inconsolable, desciende a los Infiernos en su búsqueda, logrando su propósito gracias a su canto, que conmueve a Hades y a Perséfone; el mismo Cancerbero,

${ }^{4}$ Un mito similar se presenta en el sintoísmo japonés, en relación a la pareja divina de Izanagi (el que invita) e Izanami (la que invita); esta última muere al dar a luz al dios del fuego, y cuando su esposo baja por ella a los infiernos se ve condicionado, al igual que Orfeo, a poder rescatarla si no la mira hasta haber salido; Izanagi no cumple su promesa, y al contemplar a Izanami la ve como un cadáver comido por los gusanos, y la pierde.

${ }^{5}$ Algunas versiones aducen que el padre de Orfeo fue Ciagros, dios-río hijo de Ares y rey de Tracia (región situada en los Balcanes). 
guardián de la puerta del inframundo, lame sus pies al escucharlo. A Orfeo se le concede llevar consigo a Eurídice fuera de la región infernal, con la única condición de que no la mire hasta haber salido a la luz. Orfeo no resiste la tentación, a pesar de los ruegos de ella y justo antes de salir, torna la mirada, lo que la condena a volver a los Infiernos. Caronte no cede a la insistencia de Orfeo, y se niega a llevarlo de nuevo a la otra orilla de la laguna Estigia. Orfeo vuelve a Tracia, donde desprecia a las mujeres (en alguna versión, a las bacantes, seguidoras del dios Baco) y muere a manos de ellas. Su cabeza y su lira, arrojados a un río, llegan al fin a las orillas de Lesbos, dando origen, quizá, a la tradición lírica de la isla.

\section{El drama}

La obra Orfeu da Conceição se estrenó el 26 de septiembre de 1956. La primera característica que podríamos indicar de esta pieza, cualidad metateatral pero de gran relevancia, es que se trata de la segunda obra brasileńa escrita específicamente para ser representada por actores negros. En la acotación inicial se lee: "Todas as personagens da tragédia devem ser normalmente representadas por atores da raça negra, não importando isto em que não possa ser, eventualmente, encenada com atores brancos" (Moraes, 1998). ${ }^{6}$ Destacamos este punto porque más tarde, cuando se produce la película de Camus, se mantiene esta premisa, y la totalidad de los personajes que aparecen en el filme son negros (a este respecto, ver Rodrigues Fontes, 2007).

En la historia del teatro brasileño había algún precedente, como indica Candeias (2002): "El personaje negro en el teatro no era

6 "Todos los personajes de la tragedia deben ser normalmente representados por actores de la raza negra, no importando sin embargo que pueda ser, eventualmente, llevada a escena con actores blancos". 
novedad y hay muchos de ellos en las obras abolicionistas del siglo XIX, como 'La madre' y 'El demonio familiar' de José de Alencar". 7 Y más adelante, precisando la presencia de esta raza en las representaciones habituales de la primera mitad del siglo xx: "Textos con un personaje negro, en general en papel subalterno, siempre hubo, así como la mulata sensual casi obligatoria en el teatro de revista. Pero el mismo no acontece cuando se trata de papeles más dignos y mucho menos que abra oportunidad para todo un elenco" (Candeias, 2002). Solo más tarde, en 1965, se llevaron a escena algunas obras musicales en el teatro Arena de Sao Paulo, bajo la dirección de Augusto Boal, que tenía como premisa una suerte de "realismo", como propuesta escénica alternativa a la moda imperante en Brasil. En este contexto:

Bajo el nombre de "Bossa-Arena", se realizó una vasta producción de espectáculos musicales. Entre estos destaca la serie Arena conta [...], cuya primera obra fue Arena conta Zumbi, escrita por Boal y Guarnieri, con música de Edu Lobo.

La propuesta fundamental de Zumbi fue la de destruir las convenciones teatrales utilizadas, las que se habían ido transformando en obstáculos para su propio desarrollo (Chesney Lawrence, 1997: 18).

En este caso (posterior a la obra que nos ocupa, pero relevante, dado que se trata de los pocos casos en los cuales se plantea un montaje solo para negros, en un país como Brasil, donde la mitad de la población es negra), ${ }^{8}$ de nuevo tenemos la presencia de $\mathrm{Vi}$ -

${ }^{7}$ José Martiniano de Alencar (1829-1877) dramaturgo y novelista de gran importancia; destaca su postura en contra de la discriminación (que llegaba a la esclavitud) que sufrían los negros y los guaraníes en Brasil.

${ }^{8}$ La mayor parte de las obras no indican "solo para actores blancos", pero en los hechos es una práctica habitual. 
nicio de Moraes, quien escribe la letra de original para la música "Zumbé", de Edu Lobo.

Por principio, no debería haber obras para una u otra raza, ni ningún otro tipo de discriminación; en la práctica, un Orfeo negro puede demostrar que, el problema que plantea, los sentimientos y las acciones descritas en el mito son aplicables a cualquier ser humano, en el contexto de la perspectiva sociocultural de la Grecia clásica, o bien en el ámbito del carnaval brasileño contemporáneo, en el cual, en lugar de contraponerse los espacios del mundo terrenal y los infiernos, se muestra la favela y la urbe como espacios ajenos. A este respecto, Moraes declara su intención en una breve nota periodística publicada una semana antes del estreno de Orfeu da Conceição, y aparecida más tarde como prefacio a la publicación de la obra en 1960:

Y una última palabra: esta pieza es un homenaje al negro brasileño, a quien, a fin de cuentas, se debe; y no solo por su contribución orgánica a la cultura de este país - mejor, por su apasionante estilo de vivir que me permitió, sin esfuerzo, en un simple relampaguear del pensamiento, sentir en el divino músico de la Tracia la naturaleza de uno de los divinos músicos del monte carioca (Moraes, 2003).

En cuanto a la historia que acompaña al montaje, tenemos la propia declaración del dramaturgo en relación a la preparación previa:

Es difícil prever el destino de una pieza de teatro, sobre todo cuando fue, como esta, ensayada en tres meses solo [...].

Tres meses realmente heroicos, en que un equipo de seis (el director Leo Jusi, el escenógrafo Oscar Niemeyer, el compositor Antonio Carlos Jobim, la figurinista Lila de Moraes [esposa de 
Vinicio], la coreógrafa Lina de Luca y el pintor Carlos Scliar) creó las condiciones para que un elenco de 45 figuras, con 10 actores principales, se presentara en escena (Moraes, 2003).

Desde una perspectiva crítica, no puede pasarse por alto que Orfeo, en tanto arquetipo masculino y músico (el personaje teatral, pero esta afirmación es igualmente válida para el caso de la película), es valorado por resultar atractivo a las mujeres; no suele vérsele interesado en los demás, aparte de Eurídice. La perspectiva corresponde con una visión machista, donde, de manera paradójica, pero que evidencia la complejidad de las relaciones humanas, la mujer se ve discriminada frente al hombre y sus valores de "posesión" de la mujer, con lo cual la pérdida postrera se acerca a la pérdida de un objeto de gran valor. Así, por una parte, se destaca el valor social y estético a la raza negra frente a una sociedad brasileña parcial y, por otro, se refrenda el establishment, las condiciones sociales, políticas, ideológicas centradas en el hombre (masculino), no en el ser humano.

Un modo de entender esta perspectiva en Orfeu da... es referir algunas de las escenas. Orfeo habla con su madre, Calíope, en esa estrecha relación de amor y sobreprotección que se plantea en la relación filial, tan cara a Yocasta. Cuando Orfeo explica su intención de casarse con Eurídice, la respuesta de Calíope es elocuente: "Pra que ir se amarrar, meu filho? Pensa um pouco. Você nasceu para ser livre, Orfeu! Orfeu prisioneiro" (Moraes, 1998). ${ }^{9}$ Por un lado, se hace explícito el afán de Calíope por no "perder" a su hijo y, por otro, la concepción del matrimonio como una prisión, dado que la relación amorosa, refrendada así entre una mujer y un hombre (Eurídice-Orfeo), conlleva que se coarte la "libertad" masculina. De ahí la insistencia: "Você quer

9 "'Para qué amarrarse, hijo mío? Piensa un poco. ¡Has nacido para ser libre, Orfeo! Orfeo prisionero". 
a menina? Muito bem! Fica com ela, filho [...] -mas não casa pelo amor de sua mãe. Pra que casar?" (Moraes, 1998). ${ }^{10}$ En cuanto a la propuesta de la puesta en escena, Orfeu da... no pretende ser una obra realista, en la cual la favela sea "retratada" de manera fiel. Favela refiere a los cinturones de miseria (empobrecidos, violentos en todos sentidos) de las grandes ciudades, como Río y Sao Paulo, en Brasil. "Los protagonistas son la gente de color que vive en el Morro, barrio de barracas situado en una de las cumbres que rodean la hermosa bahía de Río. Como marco de fondo [...] aprovechó el fabuloso carnaval, con sus veinticuatro horas ininterrumpidas de samba, consiguiendo ... dotar su film con unos valores espectaculares de primer orden" (Palau, 1959: 6).

Tanto el carnaval, "un elemento de subversión social [...] La exacerbación de la sexualidad y otras pasiones humanas" (Arrieta Domínguez, 2014: 141, siguiendo a Bajtin, 2003), como contexto y motivo de la acción, como el sentido de espectáculo que se mencionan en este artículo serán tratados más adelante. Estos espacios marginales se encuentran en todas las metrópolis, incluso las europeas, como muestran las cintas Brutti sporchi e cattivi (1976), de Ettore Scola, situada en los arrabales de Roma, o La haine (1995) dirigida por Mathieu Kassovitz, la cual se aproxima a los suburbios de París. Sin embargo, tanto la obra de teatro original como la adaptación cinematográfica, en tanto propuestas ficcionales, eluden la puesta en escena de la miseria de las favelas; la aproximación, por tanto, muestra una realidad idealizada, tal y como plantea Bentes (2007).

Un ejemplo más que vale referir es Cidade de Deus (2002), película brasileña dirigida por Fernando Meirelles, la cual se suma justamente a la tradición iniciada por Orfeu Negro en el tratamiento

10 "'Quieres a la niña? ¡Muy bien! Pues te quedas con ella, hijo [...] Pero no te cases, por el amor de tu madre. ¿Para qué casarse?” 
de las barriadas y sus problemáticas, pero despojando de cualquier perspectiva metafórica (hablamos en términos generales) su visión de la pobreza, de la cultura periférica y popular.

Entre otros aspectos de carácter simbólico, en el texto teatral destaca la inclusión de la Dama negra, representación de la muerte. Asimismo, el desarrollo superficial del carácter de los personajes y, sobre todo, la práctica ausencia de conflicto dramático (hay más de literatura, es decir, de narración que de drama en el texto original $)^{11}$ conduce a que sea una obra con ciertas dificultades para ser representada, si no fuera por un factor adicional: la música, compuesta exprofeso para la obra, lo cual permite una relación de sincretismo, de identificación entre un código (el lenguaje, base del drama escrito) y otro código (la doble y estrecha relación entre la notación musical y el lenguaje, presente en la letra de las canciones). ${ }^{12}$

La pieza teatral de Moraes se acerca mucho (como la película), en el ámbito de la anécdota, al mito original (al menos a la versión que tomó el autor como referencia). Sin embargo, sus aportaciones (que en estricto sentido remiten a una traducción de un código a otro, a una adaptación, tal como se definió antes) sitúan el argumento en un ámbito, quizá, más cotidiano, cercano a emociones humanas como el amor (Orfeo-Eurídice), el deseo y el odio (Aristeo), el despecho (Mira), lo que refrenda y actualiza los planteamientos del mito griego, si consideramos que el panteón helénico, la mitología que relata en primera instancia Ovidio en Las metamorfosis, describe a diosas y dioses que actúan, piensan, gozan y

${ }^{11}$ En el drama pasan cosas, una acción (dramática) se enlaza con otra, y así hasta el final; en la narración se cuentan cosas (acciones, escenarios, caracteres).

${ }^{12}$ En términos de difusión de la cultura brasileña, tanto la obra de teatro y más destacadamente la película de Camus, dieron a conocer otros ámbitos el bossanova y a dos de sus más importantes representantes, Antonio Carlos Jobim y Luiz Bonfa. 
sufren bajo parámetros plenamente humanos. Además, la propia postura de apropiación de la obra a un contexto distinto conlleva una postura ideológica particular, que confronta la tradición occidental grecolatina con el sincretismo de las poblaciones de origen negro en América, cuyo origen remite a la práctica de la esclavitud.

En este caso, Orfeu da... traslada el mito a una ucronía, a un ámbito imposible donde todos los personajes son negros, Calíope una mujer aferrada a su hijo, Apolo es descrito como un padre que prefiere mantenerse distante, Aristeo como un instrumento de la muerte (la Dama negra) y de Mira, la mujer despechada, y las bacantes, azuzadas por Mira, son instrumentos a su vez de su venganza. La obra cierra con un epílogo, formulado por el coro, que remite los valores masculinos que encarna Orfeo y, al tiempo, a la traición de que fue objeto, además de la especie de inmortalidad del canto, de la voz órfica en el mundo: "Juntaram-se a Mulher, a Morte a Lua para matar Orfeu, com tanta sorte que mataram Orfeu, a alma da rua, Orfeu, o generoso, Orfeu, o forte. Porém as três não sabem de uma coisa: para matar Orfeu não basta a Morte. Tudo morre que nasce e que viveu só não morre no mundo a voz de Orfeu". ${ }^{13}$

De este modo, los personajes se construyen de manera arquetípica, siendo representaciones, símbolos de modelos en muchos sentidos maniqueos. Parece claro que no se pretende presentar personajes de carácter realista, sino símbolos de aspectos concretos de lo humano, situado en situaciones modelo, de acuerdo con el mito clásico: por ello la conservación del coro y el corifeo, para mantener el carácter teatral, de representación en un escenario de la obra.

\footnotetext{
13 "CORO: Se juntaron la Mujer, la Muerte y la Luna para matar Orfeo, con tanta suerte que lo mataron; a Orfeo, el alma de la calle; a Orfeo, el generoso; Orfeo, el fuerte. Sin embargo, las tres no saben una cosa: para matar a Orfeo no basta la Muerte. Muere todo lo que nace y vive, pero no muere en el mundo la voz de Orfeo".
} 


\section{La película}

El Orfeu Negro (1959) de Marcel Camus ${ }^{14}$ es una "película no canónica basada en un clásico histórico", utilizando la terminología propuesta por Domingo Sánchez-Mesa.

Desde la presentación del filme, es reconocible la adscripción al mito: aparece un primer plano de un relieve clásico (esto es, de la antigüedad griega) de Orfeo y Eurídice, y sobre ellos aparece, con caracteres que remiten a la tipografía romana, el título de la película; de fondo, la pieza "A Felicidade", interpretada por el mismo Vinicio de Moraes a la guitarra con la voz de Agostinho dos Santos.

Inmediatamente, con la imagen rompiéndose en pedazos, se da la transición a la batucada ${ }^{15}$ (la irrupción del mundo negro, festivo, empobrecido de la favela que, el día antes del carnaval, se da de manera violenta, pero íntimamente ligada al mito de Orfeo): resuena la samba, la música alegre, estridente del carnaval y de un grupo de negros bailando y tocando diversos instrumentos. Samba es un término portugués proveniente de la palabra bantú de África occidental semba, que significa "invocación del espíritu de los antepasados". De este modo, la samba, el baile, se acerca al vudú en tanto ritual (pagano, festivo) de trascendencia, de suerte de posesión y abandono a la música; estos aspectos remiten claramente al don de la música de Orfeo de conmover a quien la escucha: en el sentido mítico, la música es vía para acceder al otro mundo, como lo muestra el descenso de Orfeo a los infiernos.

\footnotetext{
${ }^{14}$ No podemos olvidar Orphée (1950), de Jean Cocteau, considerada por algunos críticos como Frances Lynn y gino Wimmer (Kobal, 1994: 286, 312) como una de las mejores 10 películas de la historia.

${ }^{15}$ Castellanización del término que define la danza, con fondo de tambor, interpretada por los negros brasileños (llevados, en su origen, como esclavos desde África por los portugueses entre los siglos XVI y XIX). El batuque recuerda los golpes repetidos en el tambor.
} 
En relación a aspectos que parecieran metatextuales, como el reparto negro y el hecho de que no se tratara de actores profesionales, la exaltación de la samba en la película es de gran importancia. Hasta la década de 1930, la samba estuvo proscrita por el Estado brasileño, dado que la consideraba una expresión peligrosa de la cultura negra, de origen esclavo. Sin embargo, la samba fue ganando terreno en torno al carnaval, pero yendo más allá, y acabó legitimándose con la constitución de las escuelas, que hasta la fecha compiten por diversos premios. Como fondo en el encuadre inicial (y en muchas de las tomas posteriores), se aprecia la bahía de Río de Janeiro:

Beautifully photographed and edited, with a lot of the action on the cliffs, Rio is always an ethereal tableaux in the background, its beauty tempered by our visual anxiety of the precipice, the lurking vertigo, as if these frolicking sambistas are always just two or three wrong steps from disaster... like our involuntary falls into the chasms within our dreams (Russell, 2002). ${ }^{16}$

El primer crédito de Orfeu Negro corresponde al guión, de Jaques Viot, y el segundo reconoce: "extraido da pieça [teatral] de / vinícius de moraes / 'Orfeu da Conceição"”; sigue "Adaptação cinematográfica / de / JAQUES VIOT / MARCEL CAMUs", y la constatación de una sorpresa: "Diálogos em portugués de / VINíCIUS DE MORAEs / inspirados na versâo francesa de / JAQUES VIOT e MARCEL CAMUS". Decimos sorpresa porque, más allá de la primera

16 "Maravillosamente fotografiado y corregido, con muchas escenas situadas sobre las rocas, Río [de Janeiro] está siempre presente en los cuadros etéreos del fondo, su belleza templada por nuestra ansiedad visual del precipicio, el vértigo que está al acecho, como si quienes los personajes que bailan samba estuvieran siempre solo a dos o tres pasos en falso del desastre... como nuestras caídas involuntarias en los abismos dentro de los sueños" (la traducción es mía). 
transición del mito de Orfeo a la obra teatral de Moraes, tras la adaptación de Viot y Camus al código cinematográfico, hay una nueva traducción, que además se reconoce "inspirada" en, esto es, no referida a una traducción literal de una lengua a otra. Se trata entonces de un toma y daca, de un ir venir entre interpretaciones del mito, de su reformulación moderna en el ámbito brasileño y, por supuesto, la perspectiva que de este mundo tienen un director y un guionista europeos.

Quizá, en estricto sentido, la perspectiva que sale ganando (esto es, la que termina prevaleciendo o incidiendo mayormente sobre las otras) es la de Moraes, quien participa en aspectos tan importantes para la película como los diálogos, la interpretación musical (recordemos que las letras son suyas) y el hecho, distintivo del filme desde el título, de tratarse de una recreación de un mito en el espacio sociocultural y racial negro.

A modo de colofón, la película termina con una escena que refrenda, por una parte, uno de los pasajes simbólicos del filme: la creencia de que la música (Orfeo y su suerte de continuador, Chico, el niño que lo imita tocando la guitarra) hace salir el Sol cada mańana; por supuesto, estrechamente ligada a esta creencia, la fiesta, el baile de los niños como una celebración de vida, del mismo modo que en el mito clásico se relata que la cabeza de Orfeo y su lira siguen resonando, inspirando a los músicos. La apertura progresiva de la toma, abarcando al fondo la ciudad, Río de Janeiro (de nueva cuenta, la favela queda en un segundo plano), y más adelante la bahía, el horizonte marino, remite al futuro, y también a la leyenda que cuenta que los restos de Orfeo fueron llevados por la corriente, por el mar, hasta la orilla de la isla de Lesbos.

The brilliance of Black Orpheus is contained in both the visceral and the intellectual, as its narrative appeals to both instinct and reason. The fatalism of the lovers is a recognition of the cyclical 
movement of Time, just like Benedito's belief that the sunrise over Rio is evoked by Orpheus' love song. Mythology? Sooner or later all events become symbolism (Russell, 2002). ${ }^{17}$

Tras la escena que hemos referido, con la cual termina el filme, hay un fundido muy breve a la imagen del inicio, el relieve donde aparecen Eurídice y Orfeo. Este final reitera el origen de la anécdota, refrenda la deuda con el mito; sin embargo, debe quedar claro que se trata no solo de historias distintas, sino de discursos diversos, sistemas de signos (la literatura, el cine) que pueden coincidir, pero se constituyen de diferente modo.

\section{El nuevo Orfeo: al cine lo que es del cine}

De manera especialmente significativa, en otro paso del mito por el teatro hacia el cine, a partir del Orpheus Descending, de Tennessee Williams (1957), Sydney Lumet filma The Fugitive Kind en 1959, el mismo ańo en que se produce Orfeu Negro. La obra de Williams estaba basada en la ya referida Battle of Angels; si bien se trata solo de coincidencias, es curioso que tanto la creación de las obras de Williams y Moraes como su posterior adaptación y traducción al cine coincidan en fechas, partiendo de un referente común. En la relación entre la obra dramática y la película puede plantearse, entre otras, de la siguiente manera:

17 "El esplendor de Orfeo Negro está contenido tanto en lo visceral como en lo intelectual, así como su narrativa apela tanto al instinto como a la razón. El fatalismo de los amantes es un reconocimiento del movimiento cíclico del Tiempo, idéntica a la creencia de Benedito de que la salida del Sol sobre Río es evocada por la canción de amor de Orfeo. ¿Mitología? Tarde o temprano todos los acontecimientos se inclinan hacia el simbolismo" (la traducción es mía). 
De todos los orígenes posibles, quizá sea el teatro el que mejor se adapta a las habilidades cinematográficas. Y es por una razón. El cine adapta del teatro una forma de expresión más que un relato, mientras que adapta de la novela un relato más que una forma de expresión. [...] Tiene el cine razones para compartir un paisaje visual con el teatro [...] Cine y teatro comparten concepciones de la puesta en escena. [...] la dialéctica cine/teatro es más estrecha de lo que parece (Hernández Les, 2005: 130-131).

Esta afirmación, por una parte, clarifica las relaciones cine/teatro (la dialéctica de su quehacer, de sus diferencias), pero al tiempo simplifica, esquematiza una red compleja y aún no del todo clara. El cine, por razones históricas, es posterior a la literatura, cuya tradición facilitó (por decirlo de alguna manera) el modo en que el cine cuenta historias: hablamos de dos sistemas predominantemente narrativos.

El cine confluye en la intención con el teatro y, también, con ciertas reservas, en la parafernalia necesaria para llevarlo a cabo; en otras palabras, no basta ya con el escritor, sujeto individual, sino que hace falta un aparato que permita la realización del espectáculo. Sostiene Palau (1959: 6): "Camús [sic], en su película [...] ha rendido tributo al cine espectáculo, a un cine que tiende a convertir el film en una fiesta para los ojos"; este sentido lo alejaría de su falsa identidad con el discurso literario, predominantemente narrativo.

Pero perdemos de vista algo que, si bien es un criterio flexible, no un dogma, sirve muy bien de referencia: el teatro recurre a la imagen, al movimiento (hablamos de acción dramática), pero se basa en el diálogo, esto es, la palabra. ${ }^{18}$

${ }^{18}$ La discusión en este sentido es más amplia de lo que podemos ahora exponer; baste decir que, desde nuestra perspectiva, el teatro se basa en personajes que interactúan y dialogan (entre ellos, consigo mismos), lo demás es accesorio 
El cine, por su parte, si bien recurre al diálogo, se basa estrictamente en la imagen para contar su historia; por ejemplo, se ha señalado que el uso de la voz en off para contar al público datos de la historia va en demérito de lo cinematográfico (es un recurso fácil, manido). Uno de los aspectos en que es más sencillo seguir el proceso de trasposición, además de la anécdota, es el de los personajes.

En el caso del Orfeu Negro, los protagonistas principales conservan los nombres mitológicos: Orfeo, Eurídice, Hermes. Lo que destaca en el relato cinematográfico es la inclusión de dos personajes ayudantes (en términos de la propuesta de Propp, referida al cuento maravilloso): Benedito y Chico, quienes de muchos modos auxilian a Orfeo a lo largo de la película. Son mensajeros, guardianes, guías en distintos momentos. Pero quizá el papel más importante de estos niños sea (a partir del deseo, de la imaginación de Benedito, además de la habilidad musical de Chico) el continuar la música de Orfeo, el sentido mítico de su música que hace, en sentido figurado, que el Sol salga cada mañana sobre Río.

El filme conserva cierto sentido teatral en aspectos puntuales, como el sentido trágico de predestinación que pende como la espada de Damocles sobre Eurídice, sin explicación, sin aparente razón de ser; también en algunos de sus diálogos, como el que sostiene Orfeo con su guía al submundo, a la ceremonia vudú, en apariencia un hombre que hace la limpieza interminable de una oficina burocrática, escena que no puede dejar de remitirnos a El proceso (Orson Wells, 1962) o a Brazil (Terry Gilliam, 1985).

Pero el filme conserva un sentido alegórico sin duda cinematográfico, en tanto condiciona la manera de interpretarlo centrando la atención en símbolos: la Muerte, mirando la multitud; la multitud enardecida, partícipe y motor de la fiesta, que es otra forma

(accidental, diría Aristóteles). Otras formas teatrales, espectaculares, como la pantomima o el circo, no podrían ser consideradas así teatro. 
de narración; Eurídice que es llevada de un lado para otro por los bailarines, y, por supuesto, destaca el paso de la historia fílmica al mito griego, del realismo que muestra la pobreza y el entusiasmo del pueblo brasileño frente a la referencia, interdiscursiva, del recuento del mito que relata el funcionario del juzgado a Orfeo.

Para ilustrar esta transición cine/relato mítico, dentro de una suerte de apariencia de realidad (al menos, de verosimilitud en el discurso), vale la siguiente nota, fragmento de un artículo publicado en Espańa en octubre de 1959, tras el estreno de Orfeu Negro en Cannes:

Orfeo, sin abandonar su disfraz, sale a recorrer Río en busca de Eurídice, que ha desaparecido. Que haya quien, disfrazado, recorra las calles de la ciudad, es cosa que todo el mundo acepta, puesto que el carnaval apenas si ha terminado. Y, no obstante, gracias a esta circunstancia Camús [sic] ha podido envolver a su personaje dentro de un halo poético que le confiere la significación [mítica] que ha querido otorgarle (Palau, 1959: 22).

Hay otros claros ejemplos de recursos cinematográficos en $\mathrm{Or}$ feu Negro que la distinguen, le otorgan validez por sí misma: la persecución de Eurídice por la Muerte, corriendo por el descampado, de noche, en torno a la favela; el contraste entre la fiesta del carnaval (con escenas de los carros adornados, la multitud bailando) y Eurídice desesperada, alejada de Orfeo, a quien vemos acudiendo al jurado para recibir el premio a la mejor escuela de samba, a la mejor representación: Babilonia (no perdamos de vista el sentido pagano, religioso, de la referencia). El paso de una imagen a otra, el movimiento de la cámara en close-ups al rostro de los protagonistas intercalados en travelings y los cambios del audio (del respirar agitado del personaje al ruido del gentío, de los gritos de auxilio a la euforia de samba) son propiamente cinematográficos. Un comen- 
tario adicional (en términos históricos, ver Fléchet, 2009), sobre la recepción de la película, aparecido en una revista especializada espańola:

la "Palma de Oro", puede decirse que fue concedida por aclamación del público el mismo día de su proyección. [...] Indiscutiblemente, la mejor película del Festival, por lo que es de justicia reconocer el acierto del Jurado al concederle la "Palma de Oro". Una libre adaptación del mito de Orfeo, enmarcado en el alucinante Carnaval de Río, en un guion poético e inteligente (Ortega Frisón, 1959: 31, 37).

Por último, siempre subyacente, tenemos otra vuelta de tuerca, que remite al carácter abierto, ecléctico, comprensivo del cine: además del mito de Orfeo, de la pieza teatral de Moraes, el carnaval aparece como un elemento más para la conformación del relato fílmico. El carnaval brasileño se constituye como una narrativa específica, con personajes y acciones claramente definidas: la Reina de Noche (Mira), la Reina de Día (Eurídice), el Sol (Orfeo).

\section{A manera de conclusiones}

Podemos decir que nuestra interpretación ha planteado una relación de intermedialidad y redes de significados en la interpretación y la escritura del mito de Orfeo en el filme de Camus y los textos que le precedieron.

El cine juega así con su papel todopoderoso (como evidencia el productor televisivo en The Truman Show, Weir, 1998) y centra la historia no en el mito, sino en el carnaval, tal como lo entiende Bajtin: como una fiesta que es la vida misma y en la que "se suprimen todas las barreras jerárquicas que separan a los individuos y se establece un contacto familiar real" (2003: 152). La fiesta es celebra- 
ción, alegría y caos, transgresión social y simbólica; esencialmente, una subversión que contrasta con la imposibilidad de que el deseo de Orfeo de regresar a Eurídice de la muerte sea posible.

Cada personaje vive desde y hacia el carnaval, gira en torno a su celebración: desde Serafina -la prima de Eurídice, que ha gastado todo su dinero en el vestido que usará esa noche- hasta el propio Orfeo -que utiliza su salario para desempeñar su guitarra, esencial para la fiesta-. El carnaval es la fuerza motora de la película, lleva a los personajes a situaciones límite, propias del simbolismo que se ha señalado y de la propuesta ideológica de recrear un mito en un universo que es, a un tiempo, cercano y distante de la tradición a la que refiere.

\section{Bibliografía}

Arrieta Domínguez, Daniel, 2014, "Palimpsesto y carnavalización: 'El Orfeu Negro' de Marcel Camus”, Cuadernos de Filología Clásica. Estudios Latinos, vol. 1, núm. 34, pp. 131-142.

Bajtin, Mijail, 2003, La cultura popular en la Edad Media y el Renacimiento. El contexto

de François Rabelais, Alianza, Madrid.

Bentes, I., 2007, "Sertôes e favelas no cinema brasileiro contemporâneo: estética e cosmética da fome”, Alceu 8 , núm. 15, pp. 242-255.

Bergua, Juan B., 1960, Mitología universal, t. 1, Ediciones Ibéricas, Ávila.

Candeias, Maria Lúcia, 2002, "Análise crítica do texto Orfeu da Conceição", artículo especial para la website "Clube do Tom". Disponible en: www.jobim.com.br/colab/orfeu/analise_critica. html 
Chesney Lawrence, Luis, 1997, Las teorias dramáticas de Augusto Boal, Universidad Central de Venezuela, Facultad de Humanidades y Educación, Cuadernos de Posgrado 21, Caracas. Disponible en: www.luischesney.150m.com/OBRASLCHL/04\%20 LIBRO\%20вOAL.pdf

Cros, Edmond, 1990, De l'engendrement des forms, Centre d'études et

recherches sociocritiques-Université Paul Valéry, Montpellier.

Fléchet, A., 2009, "Um mito exótico? A recepção crítica de Orfeu negro de Marcel Camus (1959-2008)", Significação: Revista de Cultura Audiovisual, vol. 32, núm. 36, pp. 43-62.

Garcia, Alain, 1990, L'adaptation du roman au film, Diffusion, París.

Gran diccionario español-portugués português-espanhol, 2001, Espasa-Calpe, Madrid.

Guthrie, W. K. C., 2003, Orfeo y la religión griega: estudio sobre el "movimiento órfico", Siruela, Madrid.

Hernández Les, Juan A., 2005, Cine y literatura. Una metáfora visual, Ediciones JC, Madrid.

Ingarden, Roman, 1979, L'oeuvre d'art littéraire, Fundaçao Calouste Gulbenkian, Lisboa.

Kobal, John (ed.), 1994, Las 100 mejores películas, Ediciones del Prado, Madrid.

Mac Farlane, Brian, 1996, Novel to film: an introduction to the theory of adaptation, Clarendon Press, Oxford.

Meunier, Mario, 1923, La leyenda dorada de los dioses y de los héroes, Aguilar, Madrid.

Moraes, Vinicius de, 1960, Orfeu da Conceição-tragédia carioca, Livraria São José, Rio de Janeiro. 
1998, "Orfeu da Conceição", en Poesia completa e prosa, Nova Aguilar, Rio de Janeiro. Disponible en: www.viniciusdemoraes.com.br/poesia/sec_poesia_view.php?busca $=$ \&acao =list ar\&id=665\&id_tipo $=4 \&$ back_page $=1$

, 2003, "A propósito de Orfeu da Conceição", prefacio de Orfeu da Conceição - tragédia carioca, Livraria São José, Rio de Janeiro. Disponible en: www.jobim.com.br/publics/orfeu/prefacio_vin. html

Ortega Frisón, Orencio, 1959, “Cannes: xuréme. Festival International du Film”, Revista Internacional del Cine, 3a época, núm. 34, junio, pp. 28-42.

Palau, José, 1959, “El 'Orfeo negro’ de Marcel Camus”, Cine Mundo, año viII, núm. 398, 31 de octubre, pp. 8-22.

Peña Ardid, Carmen,1992, Literatura y cine: una aproximación comparativa, Cátedra, Madrid.

Pérez de Montalbán, Juan, 1991, Orfeo en lengua castellana, edición facsimilar, Ara Iovis, Madrid.

Rodrigues Fontes, E. 2007, "Corpo negro e cultura brasileira em cinco filmes nacionais: uma leitura de Cidade de Deus, Orfeu Negro, Orfeu, Madame Satã e Onibus 174', Opsis, vol. 8, núm. 7, pp. 125-138.

Russell, Lawrence, 2002, "Voodoo Samba: Marcel Camu’s Black Orpheus", Film Court. Disponible en: www.culturecourt.com/F/Latin/BlackOrpheus.htm

Villanueva, Darío, 1990, "Novela y cine, signos de narración ”, en Carmen Peńa Ardid (coord.), Encuentros sobre literatura y cine, Instituto de Estudios Turolenses, Teruel, pp. 186-209.

Virgilio, Plubio, 1967, “Geórgicas”, Obras completas, Aguilar, Madrid, pp. 93-170.

Wolf, Sergio, 2001, Cine/Literatura. Ritos de pasaje, Paidós, Lanús, Argentina. 